\title{
Current Harmonic Compensation and Power Factor Improvement by Hybrid Shunt Active Power Filter
}

\author{
T.Mahalekshmi \\ Assistant Professor, \\ Mepco Schlenk Engineering College, \\ Sivakasi, India
}

\begin{abstract}
In this paper the current harmonic can be compensated by using the Shunt Active Power Filter, Passive Power Filter and the combination of both. The system has the function of voltage stability, and harmonic suppression. The reference current can be calculated by dq transformation. An improved generalized integrator control was proposed to improve the performance of APF. The simulation results of the non- linear systems have been carried out with MATLAB 7.6.
\end{abstract}

\section{KEY WORDS}

Generalized integrator controller, Active power filter (APF), harmonic suppression, voltage stability.

\section{INTRODUCTION}

The growing use of electronic equipment produces a large amount of harmonics in the power distribution systems because of non-sinusoidal currents consumed by non-linear loads. Some of the examples for non-linear loads are diode-rectifiers, thyristor converters, adjustable speed drives, furnaces, computer power supplies, uninterruptible power supplies, etc. Even though these devices are economical, flexible and energy efficient, they may degrade power quality by creating harmonic currents and consuming excessive reactive power. The above phenomena can cause many problems such as resonance, excessive neural currents, low power factor etc.

Harmonic distortion in power distribution systems can be suppressed using two approaches namely, passive and active powering. The passive filtering is the simplest conventional solution to mitigate the harmonic distortion. Although simple, the use passive elements do not always respond correctly to the dynamics of the power distribution systems. Over the years, these passive filters have developed to high level of sophistication. Some even tuned to bypass specific harmonic frequencies.

Conventional passive filters consist of inductance, capacitance, and resistance elements configured and tuned to control the harmonics. The singletuned "notch" filter is the most common and economical type of passive filter. The notch filter is connected in shunt with the power distribution system and is series-tuned to present low impedance to a particular harmonic current. Thus, harmonic currents are diverted from their normal flow path through the filter. Another popular type of passive filter is the high-pass filter (HPF). Passive LC filters are generally used to reduce these problems, but they have many de-merits such as its being bulk and heavy, and its resonance, tuning problem, fixed compensation, noise, increased losses, etc. On the contrary, the APF can solve the aforementioned problems and is often used to compensate current harmonics and low power factor that is caused by non-linear loads.
In an APF connection, it was roughly classified as in series (series APF) and in parallel (shunt APF). In this paper the combination of both passive power filter and Active power filter can be implemented to suppress the harmonics.

\section{CONFIGURATION OF THE SYSTEM}

Fig. 1 shows a proposed system consisting of a Shunt active power filter and Passive filter. The purpose of using this combined system is to reduce the harmonics effectively. The power factor also improved by using the combined system.

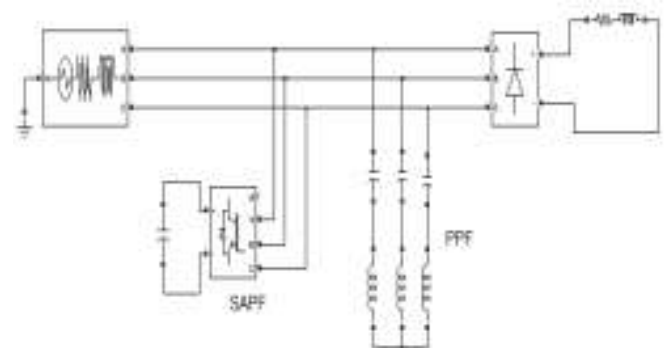

Figure 1 Combination of shunt active filter and passive filter

The main circuit of the active filter is the PWM inverter using IGBT. The PWM inverter has a dc capacitance of $2000 \mu \mathrm{F}$.

\section{SHUNT ACTIVE POWER FILTER}

\subsection{Control Circuit of Shunt Active Filter}

The overall control circuit of shunt active filter is shown in Figure 2 The Reference current is calculated by abc to dq transformation technique. The output of the reference current calculation in compared with the output of the shunt active filter, the error signal is given to the Improved Generalized integrator controller (IGIC). The pulses can be generated using PWM generator and given to the inverter to produce the compensating current.

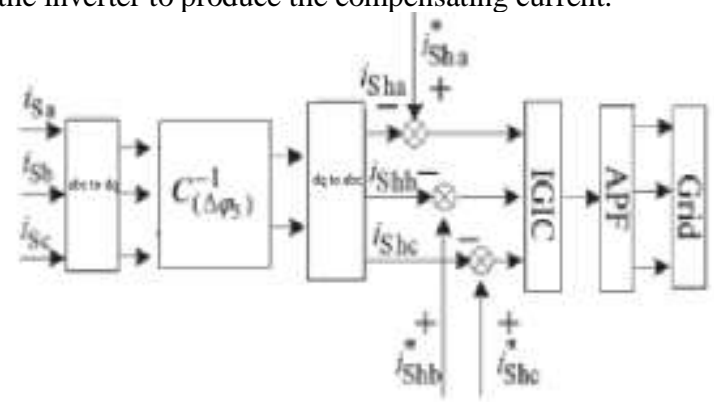

Figure 2 Overall control circuit of SAPF 


\subsection{Reference Current Calculation}

The reference current can be calculated using the $\mathrm{dq}$ transformation technique. The load current is given to the abc to dq transformation module. The output is given to the $C_{\triangle q}^{-1}$ block which is given by

$C_{\left(\Delta \varphi_{i}\right) n}^{-1}=\left[\begin{array}{cc}\sin \left(n \omega t+\Delta \varphi_{n}\right) & -\cos \left(n \omega t+\Delta \varphi_{n}\right) \\ -\cos \left(n \omega t+\Delta \varphi_{n}\right) & -\sin \left(n \omega t+\Delta \varphi_{n}\right)\end{array}\right]$

The simulation diagram for reference current calculation is shown in Figure 3 The input of the reference current calculator is the load current. The load current is the combination of the harmonic current and the fundamental current. But the output of the reference current calculator is the fundamental current.

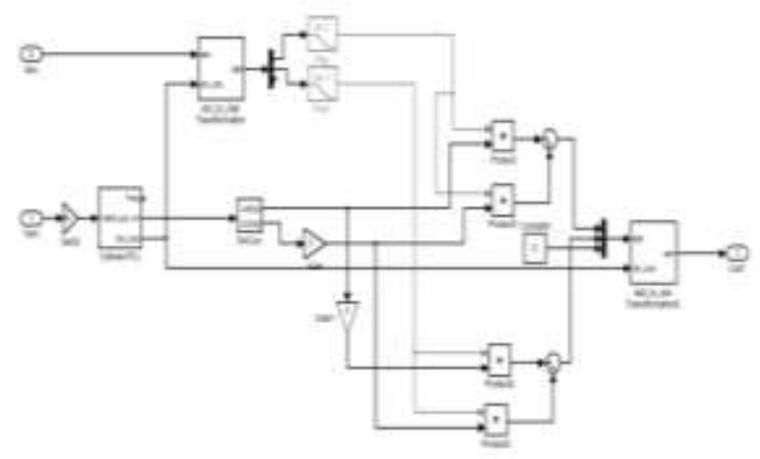

Figure 3 Reference current calculation

\subsection{Improved generalised Integrator controller}

An improved generalized integrator control (IGIC) was proposed to increase the performance of harmonic suppression. IGIC is a PI controller used to eliminate error between the filter current and the harmonic current. It consists of several PI controller. Each controller is tuned to reduce the particular harmonics. The structure of Improved Generalized Integrator Controller (IGIC) is shown in Figure 5.

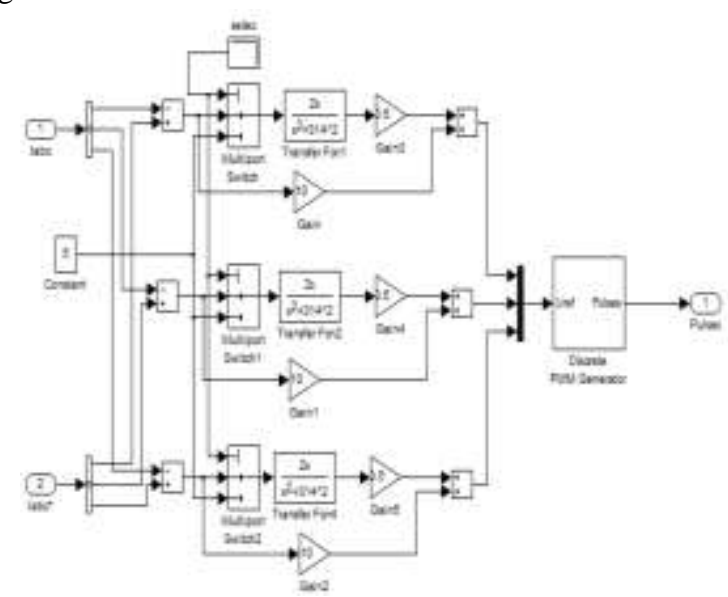

Figure 5 PI controller using the stationary-frame generalized integrators.

\section{SIMULATION RESULTS}

The simulation results are compared with the control method of Passive Power Filter, Active Power Filter and the combination of Passive Power Filter and Active Power Filter.

\subsection{Results For passive Power Filter}

The simulation diagram with Passive Power Filter is shown in Figure 4. The diagram consists of the source, non-linear load and Passive Power Filter

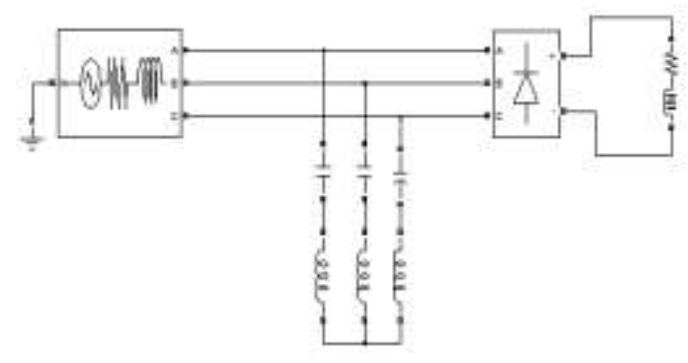

Figure 4 Simulation diagram with PPF

Figure 5 shows the waveform of supply current before compensation. It consist of fundamental current as well as the harmonic current due to the non-linear load

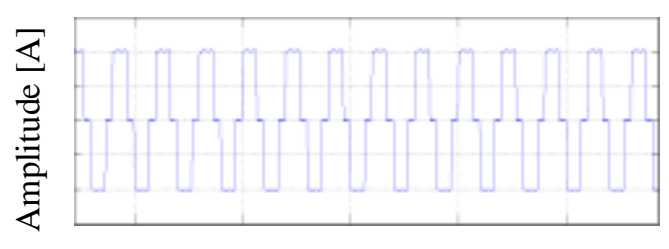

Time(s)

Figure 5 Supply current waveform -before compensation

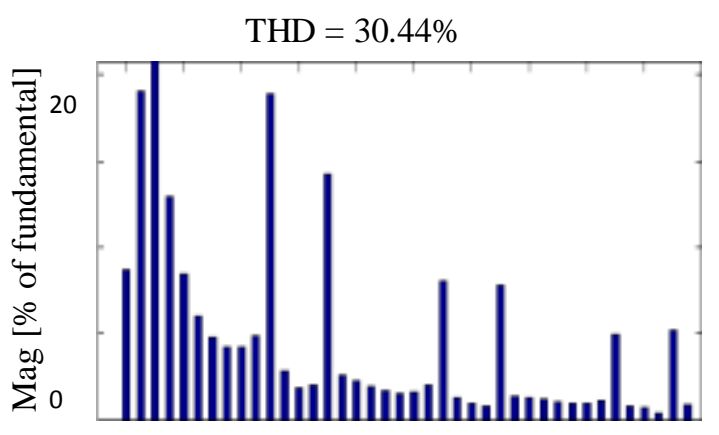

Harmonic order

Figure 6 Spectrum analysis of supply current-Before compensation

Fig.6 shows the spectrum analysis of supply current before compensation. The Total Harmonic Distortion of the 
supply current is $30.44 \%$. Figure 7 shows the waveform of supply current after compensation. It consist of fundamental current only. The harmonic current present in the supply current is eleminated by using the Passive Power Filter.

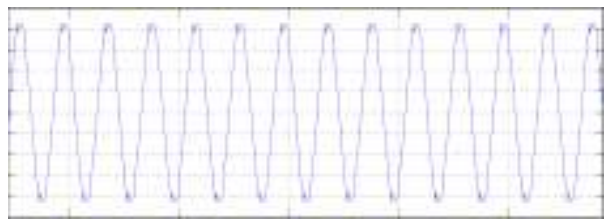

Time(s)

Figure 7 Supply current waveform -after compensation using PPF

Figure 8 shows the spectrum analysis of supply current after compensation. The Total Harmonic Distortion of the supply current is reduced to $4.10 \%$ from $30.44 \%$.

$\mathrm{THD}=4.96 \%$

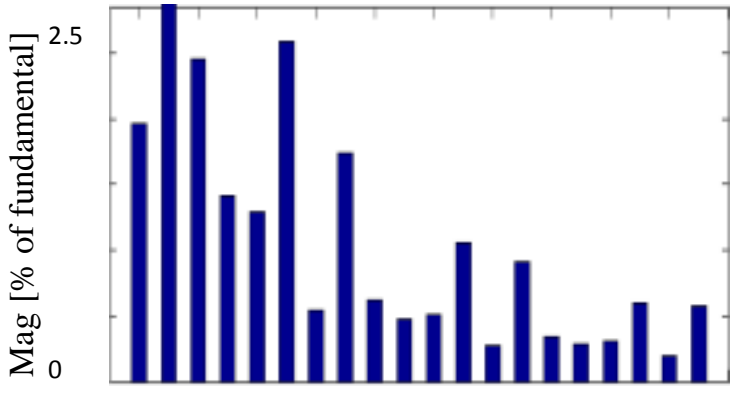

Harmonic order

Figure 8 Spectrum analysis of supply current- after compensation using PPF

\subsection{Results For Shunt Active Power Filter}

The simulation diagram with shunt Active Power Filter is shown in Figure 9. The diagram consists of the source, non-linear load, shunt Active Power Filter and its control circuit.

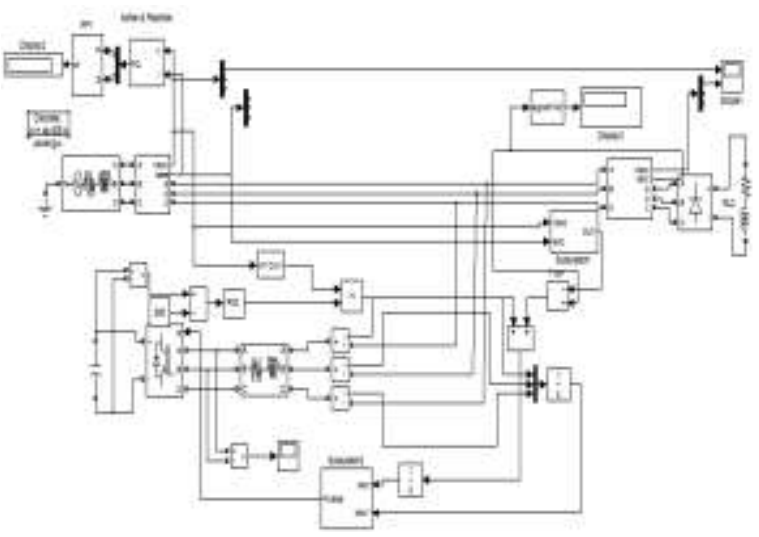

Figure 9 Simulation diagram with SAPF
Figure 10 shows the waveform of supply current after compensation. It consist of fundamental current only. The harmonic current present in the supply current is eleminated by using the Shunt Active Power Filter. The distortion present in the supply current is reduced when compared to PPF compensation

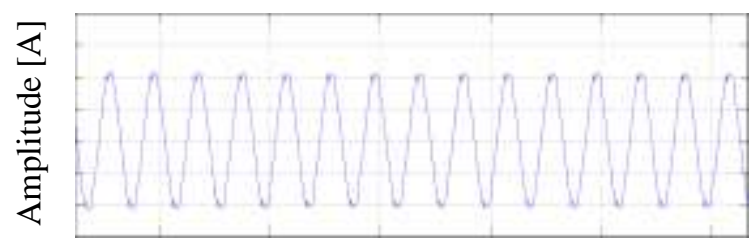

Time(s)

Figure 10 Supply current waveform -after compensation using SAPF

Figure 11 shows the spectrum analysis of supply current after compensation. The Total Harmonic Distortion of the supply current is reduced to $4.85 \%$ from $30.44 \%$

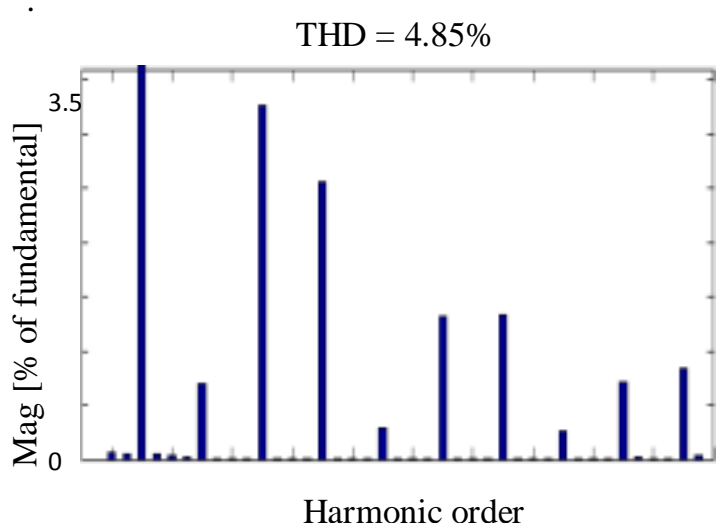

Figure 11 Spectrum analysis of supply current- after compensation using SAPF

\subsection{Results For the combination of shunt Active Power Filter and Passive Power Filter}

The simulation diagram with shunt Active Power Filter and PPF is shown in Fig.12. The diagram consists of the source, non-linear load, Passive Power Filter, shunt Active Power Filter and its control circuit.

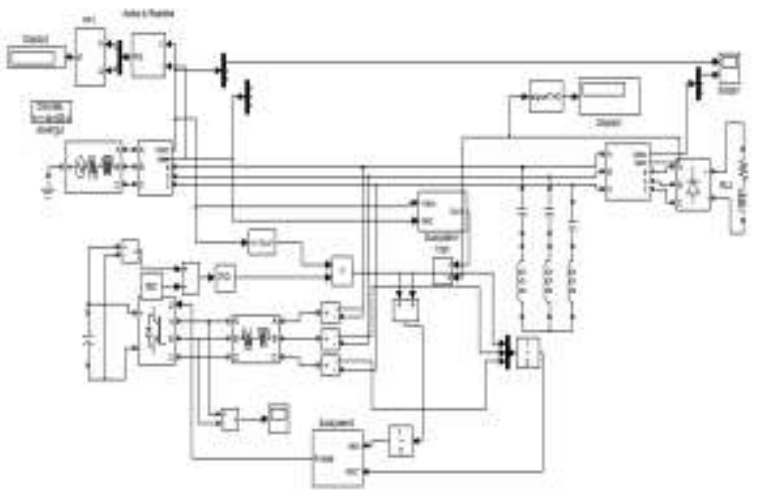

Figure 12 simulation diagram with SAPF and PPF 
Figure 13 shows the waveform of supply current after compensation. The waveform is more sinusoidal when compared to other two techniques.

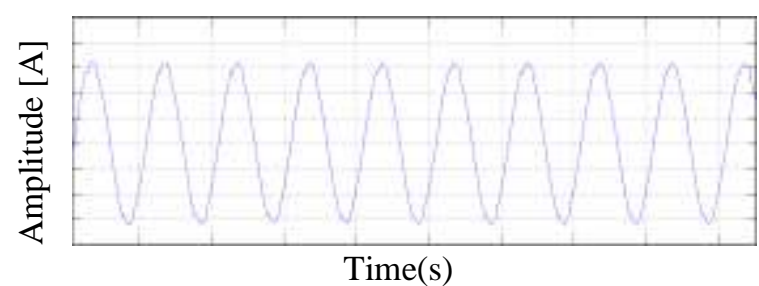

Figure 13 Supply current waveform -after compensation using SAPF and PPF

Figure 14 shows the spectrum analysis of supply current after compensation. The Total Harmonic Distortion of the supply current is reduced to $1.95 \%$ from $30.44 \%$

$\mathrm{THD}=1.95 \%$

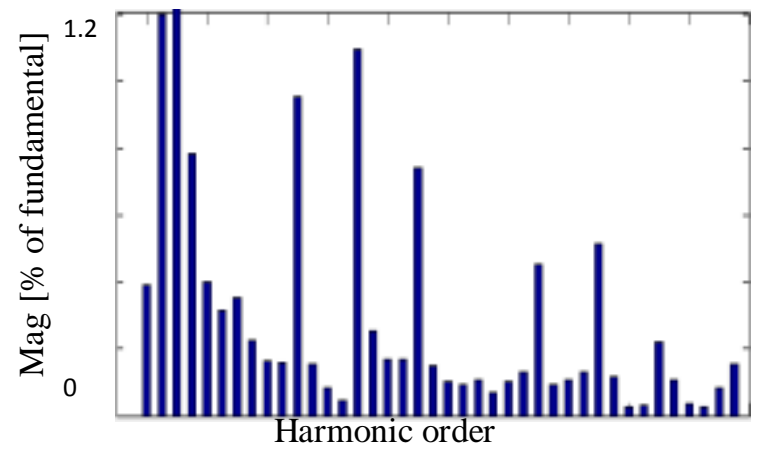

Figure 14 Spectrum analysis of supply current- after compensation uing SAPF and PPF

\subsection{Comparison of Results}

The numarical values of the harmonics are listed in table 1. The comparisons are made between before compensation, Shunt Active Filter and the combination of Shunt Active Power Filter and Shunt passive Filter.

Table 1. Comparison of \% of harmonics

\begin{tabular}{|c|c|c|c|}
\hline \multirow{2}{*}{$\begin{array}{c}\text { Harmonic } \\
\text { order }\end{array}$} & \multicolumn{3}{|c|}{ \% of harmonics } \\
\cline { 2 - 4 } & $\begin{array}{c}\text { Before } \\
\text { Compensation }\end{array}$ & SAPF & $\begin{array}{c}\text { SAPF } \\
+ \\
\text { PPF }\end{array}$ \\
\hline $3^{\text {rd }}$ & 4.79 & 0.70 & 0.35 \\
\hline $5^{\text {th }}$ & 18.91 & 3.28 & 0.96 \\
\hline $7^{\text {th }}$ & 14.24 & 2.56 & 1.10 \\
\hline $9^{\text {th }}$ & 1.16 & 0.89 & 0.74 \\
\hline $11^{\text {th }}$ & 1.66 & 1.33 & 0.11 \\
\hline $13^{\text {th }}$ & 7.75 & 1.34 & 0.45 \\
\hline
\end{tabular}

Table 1 shows the comparison chart of harmonic order. The $\%$ of harmonics can be reduced in the combination of Shunt Active Filter and Passive Power Filter when compared to Passive Power Filter alone. For the comparison only even order harmonics only considered. The graphical representation of the values are shown in fig. 15.

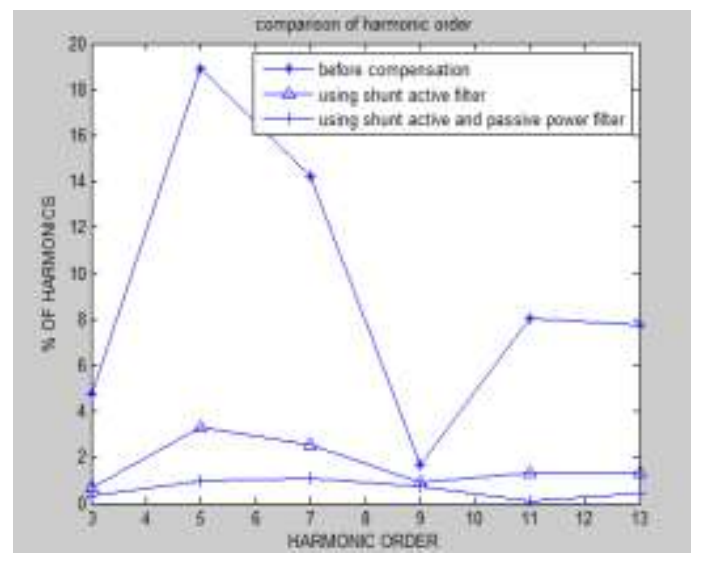

Figure 15 Graphical representation of harmonic order

Table 2 shows the $\%$ of THD of PPF, SAPF and the combination of SAPF and PPF. When compared to all methods the $\%$ of THD can be reduced to1.95\% by the combination of the two methods.

Table 2. Comparison of \% of THD

\begin{tabular}{|c|c|}
\hline SYSTEM & \% of THD \\
\hline Before compensation & 30.44 \\
\hline Passive Power Filter & 4.96 \\
\hline $\begin{array}{c}\text { Shunt Active Power Filter } \\
\text { Combination of Shunt Active } \\
\text { power Filter and Passive power } \\
\text { Filter }\end{array}$ & 4.85 \\
\hline
\end{tabular}

Table 3. Comparison of Power factor

\begin{tabular}{|c|c|}
\hline SYSTEM & $\begin{array}{c}\text { POWER } \\
\text { FACTOR }\end{array}$ \\
\hline Passive Power Filter & 0.9218 \\
\hline Shunt Active Power Filter & 0.9547 \\
\hline $\begin{array}{c}\text { Combination of Shunt Active } \\
\text { power Filter and Passive }\end{array}$ & 0.9554 \\
\hline
\end{tabular}




\begin{tabular}{|l|l|}
\hline power Filter & \\
\hline
\end{tabular}

As listed in table 3 the power factor also improved to 0.9554 when compared to other two methods.

Table 4. System parameters

\begin{tabular}{|c|c|}
\hline $\begin{array}{c}\text { SYSTEM } \\
\text { PARAMETERS }\end{array}$ & VALUES \\
\hline Source impedance & $\begin{array}{c}\mathrm{R}=0.5 \mathrm{ohm} \\
\mathrm{L}=1 \mathrm{mH}\end{array}$ \\
\hline Load & $\begin{array}{c}\mathrm{R}=10.6 \mathrm{ohm} \\
\mathrm{L}=58.2 \mathrm{mH}\end{array}$ \\
\hline PPF & $\mathrm{C}=625 \mu \mathrm{F}$ \\
& $\mathrm{L}=20.17 \mathrm{mH}$ \\
\hline SAPF & $\mathrm{R}=0.001 \mathrm{ohm}$ \\
& $\mathrm{L}=3.5 \mathrm{mH}$ \\
\hline
\end{tabular}

Table 4 gives the system parameters of the simulation system.

\section{CONCLUSION}

The system of Passive power Filter, Shunt Active Power Filter and the combination of Passive power Filter and Shunt Active Power Filter is proposed in this work. Improved generalised Integrator controller is proposed here. When compared to the three methods the combination of Passive power Filter and Shunt Active Power Filter is efficient for harmonic suppression and power factor improvement. By this method the \% of THD can be reduced to 1.95 and the power factor is increased to 0.9554 .

\section{REFERENCES}

[1] An Luo, Zhikang Shuai, Wenji Zhu, and Z. John Shen," Combined System for Harmonic Suppression and Reactive Power Compensation" IEEE Transactions on Industrial Electronics, Vol. 56, no. 2, February 2009.

[2] C.K.Duffey and R.P.Stratford, "Update of Harmonic Standard IEEE-5 19: Recommended Practices and Requirements for Harmonic Control in Electric Power Supply Systems." IEEE Trans. IAS, pp. 1025-1034, Nov/Dec. 1989.

[3] J.-C. Wu, H.-L. Jou, and Y.-T. Feng, "Novel circuit topology for three-phase active Power filter," IEEE Trans. Power Del., vol. 22, no. 1, pp. 444-449, Jan. 2007.
[4] S Z. Shuai, A. Luo, R. Fan et al, "Injection branch design of injection type hybrid active power filter," Autom. Elect. Power Syst., vol. 31, no. 5, pp. 57-60, Jun. 2007

[5] M. H. Abdel-Rahman, F. M. H. Youssef, and A. A. Saber, "New static var compensator control strategy and coordination with under-load tap changer," IEEE Trans. Power Del., vol. 21, no. 3, pp. 1630-1635 Jul. 2006

[6] X. Yuan, W. Merk, H. Stemmler et al., Stationaryframe generalized integrators for current control of active power filters with zero steady-state error for current harmonics of concern under unbalanced and distorted operating conditions," IEEE Trans. Ind. Appl., vol. 38, no. 2, pp. 523-532, Mar. /Apr. 2002.

[7] Q . Tan,W. Li, L. Chang, and H. Huang, "A hybrid neuro-fuzzy system For robot control," in Proc. IEEE Int. Conf. Intell. Syst. 21st Century, 1995, pp. 2916-2921.

[8] Z. Chengyong, L. Xiangdong, and L. Guangkai, "Parameters Optimization of VSC-HVDC control system based on simplex algorithm," in Proc. IEEE Power Eng. Soc. General Meeting, 2007, pp. 1-7.

[9] C.K.Duffey and R.P.Stratford, "Update of Harmonic Standard IEEE-519: Recommended Practices and Requirements for Harmonic Control in Electric Power Supply Systems." IEEE Trans. IAS, pp. 10251034, Nov/Dec. 1989.

[10] Hirofumi Akagi, Fellow, "New trends in active filter for power conditioning", IEEE Transaction on Industry Applications, Vol 32, no6. November/December 1996.

[11] K.-K. Shyu, M.-J. Yang, Y.-M. Chen, and Y.-F. Lin, "Model reference adaptive control design for a shunt active-power-filter system," IEEE Trans. Ind. Electron., vol. 55, no. 1, pp. 97-106, Jan. 2008.

[12] L. Malesani, L. Rossetto, and P. Tenti, "Active filter for reactive power and harmonics compensation,"in Proc. IEEE PESC'86, 1986, pp.321-330.

[13] T. M. Rowan and R. J. Kerkman, "A new synchronous current regulator and an analysis of current regulated PWM inverters," IEEE Trans. Ind. Applicat., vol. IA-22, pp. 678-690, July/Aug. 1986.

[14] S. A. Gonzalez, R. Garcia-Retegui, and M. Benedetti, "Harmonic computation technique suitable for active power filters," IEEE Trans. Ind. Electron., vol. 54, no. 5, pp. 2791-2796, Oct. 2007.

[15] K.M. Cho,W. S. Oh, Y. T. Kim, and H. J. Kim, “A new switching strategy for pulse width modulation (PWM) power converters," IEEE Trans. Ind. Electron., vol. 54, no. 1, pp. 330-337, Feb. 2007. 